\title{
Predictive Value of the Clock Drawing Test
}

\author{
A Review of the Literature \\ Ruth Peters Elisabete M. Pinto \\ Care of the Elderly, Imperial College Faculty of Medicine, Hammersmith Campus, London, UK
}

\section{Key Words}

Cognitive decline, early diagnosis - Cognitive tests •

Cognitive decline, early detection · Elderly

\begin{abstract}
Background/Aims: The Clock Drawing Test (CDT) assesses cognition focusing on executive function and praxis in contrast to the more language-based Mini-Mental State Exam. The CDT may allow early identification of cognitive decline. Methods: A systematic review of the literature was used to identify studies that had used the CDT to predict future cognitive impairment. Results: Five studies were found with the CDT as a predictor. The data were too disparate for metaanalytic techniques. Conclusion: The CDT may be a useful tool to identify decline before more traditional screening tests; however, further studies are needed as the data are sparse and heterogeneous.

Copyright $\odot 2008$ S. Karger AG, Base
\end{abstract}

\section{Introduction}

Dementia is a common form of illness and cause of disability in the very elderly [1] and we live in a globally ageing society [2]. Treatments to ameliorate the effects of dementia are available [3] and advance warning of this disease may allow time to implement treatment strategies and to plan ahead. There are many cognitive tests and diagnostic criteria for the identification of cognitive decline, mild cognitive impairment (sometimes thought of as a preclinical phase of dementia) and dementia itself [4, 5]. Probably the most widely used is the Mini-Mental State Exam (MMSE) [6, 7], a tool which is fairly easily administered with relatively little training and takes approximately $30 \mathrm{~min}$ to complete [6]. The disadvantages faced by the MMSE are that it is language based [4] and if not administered in the first language of the individual could result in a lower score. This might be of particular relevance when assessing the elderly from ethnic minority groups, although multiple language versions are available to help surmount this problem. The MMSE is also thought to be influenced by education [4], such that lower levels of education result in lower scores especially for the language-based items. High levels of education also have an impact as this can contribute to ceiling effects with the educated individuals able to use their cognitive reserve to perform well on the MMSE despite having a decline from normal functioning $[4,8,9]$.

Supplementing the standard MMSE with the Clock Drawing Test (CDT) has been proposed [10]. This may help compensate for these disadvantages as the latter requires less language ability and performance in executive function and praxis may be less protected by cognitive reserve. The CDT has been in use since the 1950s [4] and is easy to administer [7]. It is also considered to be less influenced by depression or dysphoria $[11,12]$. The clock test is thought to require the use of a variety of mental

\section{KARGER \\ Fax +4161306 1234 \\ E-Mail karger@karger.ch}

www.karger.com
(C) 2008 S. Karger AG, Basel

$1420-8008 / 08 / 0264-0351 \$ 24.50 / 0$

Accessible online at:

www.karger.com/dem
Ruth Peters

Care of the Elderly, Imperial College Faculty of Medicine, Hammersmith Campus

Du Cane Road

London W12 0NN (UK)

Tel. +44 208383 3959, Fax +44 208383 3378, E-Mail r.peters@imperial.ac.uk 
Table 1. The papers identified in the literature

\begin{tabular}{|c|c|c|c|c|c|}
\hline Authors & Study details & Participant details & Time delay & Screening tools used & $\begin{array}{l}\text { Dementia } \\
\text { diagnosis }\end{array}$ \\
\hline \multicolumn{6}{|c|}{ Studies with information on the CDT as a predictor } \\
\hline $\begin{array}{l}\text { Ferrucci } \\
\text { et al. [21], } \\
1996\end{array}$ & $\begin{array}{l}\text { to evaluate the CDT as } \\
\text { predicting cognitive } \\
\text { decline; } \\
\text { observational }\end{array}$ & 247 followed for 4 years & $\begin{array}{l}\text { baseline for this analysis = } \\
\text { 1991; } \\
\text { follow-up }=1995\end{array}$ & $\begin{array}{l}\text { at baseline 1991: } \\
\text { MMSE, } \\
\text { CDT, } \\
\text { Dementia Rating Scale; } \\
\text { in 1995: } \\
\text { MMSE, } \\
\text { Dementia Rating Scale }\end{array}$ & $\begin{array}{l}\mathrm{N} / \mathrm{A} \text {, just } \\
\text { assessed } \\
\text { cognitive } \\
\text { function }\end{array}$ \\
\hline $\begin{array}{l}\text { Chen } \\
\text { et al. [22], } \\
2001\end{array}$ & $\begin{array}{l}\text { prospective community- } \\
\text { based study; } \\
\text { case control methods } \\
\text { used to compare }\end{array}$ & $\begin{array}{l}551 \text { participants; } \\
68 \text { cases developed } \\
\text { symptomatic Alzheimer's } \\
\text { disease and had full testing } \\
\text { data }\end{array}$ & $\begin{array}{l}\text { assessment at ' } 3.5(\mathrm{~T} 1) \\
\text { and } 1.5(\mathrm{~T} 2) \\
\text { years before onset' }\end{array}$ & $\begin{array}{l}\text { neuropsychological battery, } \\
\text { CDT }\end{array}$ & $\begin{array}{l}\text { standard } \\
\text { criteria }\end{array}$ \\
\hline
\end{tabular}

\begin{tabular}{|c|c|c|c|c|c|}
\hline $\begin{array}{l}\text { O’Rourke } \\
\text { et al. [23], } \\
1997\end{array}$ & prospective & $\begin{array}{l}59 \text { recruited from a clinic for } \\
\text { Alzheimer's disease }\end{array}$ & $\begin{array}{l}\text { average time between } \\
\text { baseline }(\mathrm{T} 1) \text { and } \\
\text { later }(\mathrm{T} 2) \text { assessments = } \\
22 \text { months }\end{array}$ & $\begin{array}{l}\text { clock tests (scoring system } \\
\text { Tuokko), } \\
\text { CDT administered at first visit } \\
\text { (T1) }\end{array}$ & $\begin{array}{l}\text { standard } \\
\text { criteria }\end{array}$ \\
\hline $\begin{array}{l}\text { Brodaty } \\
\text { and Moore } \\
{[24], 1997}\end{array}$ & $\begin{array}{l}\text { cross-sectional case } \\
\text { control study }\end{array}$ & $\begin{array}{l}\text { subset } 8 / 28 \text { subjects had } \\
\text { Alzheimer's disease and } \\
\text { MMSE } \geq 24\end{array}$ & none & MMSE & $\begin{array}{l}\text { standard } \\
\text { criteria }\end{array}$ \\
\hline $\begin{array}{l}\text { Ratcliff } \\
\text { et al. [25], } \\
2003\end{array}$ & $\begin{array}{l}\text { prospective } \\
\text { observational study }\end{array}$ & $\begin{array}{l}425 \text { completed tests in all } \\
\text { assessment years }\end{array}$ & $\begin{array}{l}10 \text { years } \\
\text { assessments every } 2 \text { years }\end{array}$ & $\begin{array}{l}\text { MMSE, } \\
\text { neuropsychological battery, } \\
\text { CDT }\end{array}$ & none \\
\hline
\end{tabular}

\begin{tabular}{|c|c|c|c|c|c|}
\hline \multicolumn{6}{|c|}{ Studies without information on the CDT as a predictor } \\
\hline $\begin{array}{l}\text { Lee } \\
\text { et al. [26], } \\
2003\end{array}$ & prospective pilot survey & $\begin{array}{l}50 \text { consecutive referrals to an } \\
\text { outpatient ophthalmology } \\
\text { clinic aged }>64 \text { years }\end{array}$ & $\begin{array}{l}\text { not clear; only } 1 \text { patient } \\
\text { accepted referral after } \\
\text { screening }\end{array}$ & $\begin{array}{l}\text { clock drawing (plus depression } \\
\text { and functional impairment } \\
\text { screen) }\end{array}$ & none \\
\hline $\begin{array}{l}\text { Nishiwaki } \\
\text { et al. [27], } \\
2004\end{array}$ & prospective trial & $\begin{array}{l}13,557 \text { participants } \geq 75 \text { years; } \\
\text { community-based sample }\end{array}$ & $\begin{array}{l}\text { median follow-up }= \\
4.7 \text { years }\end{array}$ & $\begin{array}{l}\text { MMSE, CDT - scored using a } \\
\text { 4-point method }\end{array}$ & none \\
\hline $\begin{array}{l}\text { Ganguli } \\
\text { et al. [28], } \\
1996\end{array}$ & $\begin{array}{l}\text { prospective } \\
\text { observational study }\end{array}$ & $\begin{array}{l}\text { follow-up sample }(\mathrm{n}=1,017 \\
\text { mean age }=74.3 \text { years, } \\
\text { standard deviation }=5.4)\end{array}$ & $\begin{array}{l}\text { first follow-up } \\
\text { (mean }=23.8 \text { months, } \\
\text { standard deviation }=2.8 \text { ) }\end{array}$ & $\begin{array}{l}\text { MMSE, } \\
\text { neuropsychological battery, } \\
\text { CDT }\end{array}$ & none \\
\hline
\end{tabular}

skills; visuo-perceptual and visuo-motor abilities to internally represent the clock face and to translate the mental representation into a motor program, and visuo-perception also guides the ongoing layout of the clock and monitors the output. Hemi-attentional processes are needed to produce features on both sides of space, the linguistic system must provide the graphomotor representation on numbers and executive function must coordinate the planning, organisation and simultaneous processing. This includes corrections and inhibition of incorrect responses such as perseveration [13]. Memory is needed to remember the instruction to set the time and retrieve it once the clock face is complete, and finally the time setting of 10 past 11 with the 2 recoded as $10 \mathrm{~min}$ past the hour 'cannot be stimulus driven but must rely on executive function' [13]. There are several methods for administering the clock test, but most authors agree that the clock draws primarily on visuo-spatial and executive 
Outcome

The CDT was scored according to the system of Wolf-Klein; pathological clocks correlated with follow-up MMSE score $(\mathrm{p}<0.01)$; when analysis was restricted to those with an MMSE score $>21$ at baseline, people with a pathological clock at baseline were 5.4 times more likely to have an MMSE score $<21$ at follow-up (confidence interval $=2.1-14.2$ ) and 5 times more likely to have an MMSE score $<18$ at follow-up (confidence interval 1.619.6)

Mean change between cases and controls: for the MMSE cases declined from 26.68 to $25.94(\mathrm{p}=0.2)$, controls from 27.76 to $27.61(\mathrm{p}=0.52)$, the difference was significant $(\mathrm{p}=0.04)$; difference in decline/change between cases and controls: for the CDT, when the changes in cases and controls were compared directly, the $\mathrm{p}$ value was 0.11 ; the participants were not demented at their second assessment

Predrawn circle; the participants were not suffering from dementia at their first assessment; 18 had a diagnosis of dementia at follow-up assessment; the 2 groups differed in their baseline CDT score; when each error type and clock setting/reading errors were entered into a MANCOVA (adjusted for age) substitution $(\mathrm{p}=0.006)$ and clock setting $(\mathrm{p}=0.001)$ remained significant

The Shulman scale identified 7/8 using a cut-off of $2 / 3$; the Sunderland scale identified $3 / 8$ with a cut-off of $5 / 6$ or $5 / 8$ using a cut-off of $8 / 9$; the Wolf-Klein scale identified $1 / 8$ using a $6 / 7$ cut-off or $7 / 8$ with a cut- off of $8 / 9$

The participants included in this analysis were cognitively intact at baseline; factor analysis identified several factors, although there was some change in the loading as the assessments progressed; the factors included constructional praxis (including clock test); the authors recommend caution regarding the praxis data as these tests are subject to ceiling effects

10 participants had abnormal clock scores, but only 1 accepted further assessment, so judgement of predictive value was not possible

CDT associated with mortality from cerebrovascular disease, respiratory disease and malignant neoplasm; incident dementia not assessed

The participants included in this analysis were cognitively intact at baseline; cognition showed a slight decline; the mean clock scores fell from 7.4 to 7.1 ; no information is given on the predictive status of the clock scores, although the participants who dropped out of the study before follow-up assessment were more likely to have been impaired at baseline

functioning, particularly with regard to the inhibition of incorrect responses [14-17].

The CDT then may focus differently to the standard MMSE, and this be especially relevant as the earliest deficits that are manifested in Alzheimer's disease, the commonest form of dementia, may be visuo-spatial [14] or visuo-spatial and executive functioning, even in those with high MMSE values [15]. Preclinical Alzheimer's disease has been associated with attention and executive function deficits [16]. Similar findings with deficits in memory and executive function were shown in a further study [18].

A variant of the CDT, 'Clox', was able to distinguish between Alzheimer's disease and mild cognitive impairment, finding that subjects with mild cognitive impairment had worse verbal, visuo-spatial and executive function skills than control subjects [19]. A further study also found impaired executive function Alzheimer's disease and scores unaffected by dysphoria, although apathy caused them to fall [20].

Vascular dementia, the second most frequent diagnosis, and frontotemporal dementia are also thought to show deficits in executive functioning $[17,14]$.

The CDT may then be an apt means of measuring early cognitive decline, possibly before MMSE or other screening tests.

The objective of this review was to systematically examine the literature to discover any evidence that the use of the CDT had been assessed as an early screen for possible dementia, before the more usual tests had identified a problem.

\section{Method}

Three databases were searched for the terms 'Clock drawing test' or 'clock drawing task' or 'clock test' or 'clock drawing' or 'CDT' or 'clock' with 'cognitive decline' or 'cognitive impairment' or 'executive function'. The searches were restricted to subjects $\geq 65$ years, human sources and in English, French, Spanish, Italian and Portuguese languages.

Psychinfo was searched from 1967 to January 2006, Medline from 1966 to January 2006 and Embase from 1980 to January 2006. In total 288 records were identified. The number of abstracts selected for further examination was 138. Abstracts were selected if they used the clock test or a variant of this to assess cognitive function (i.e. not as a proxy for physical function, etc.) and if the participants were not suffering from any additional psychiatric disorders which may affect performance on cognitive testing. Letters, conference proceedings and case studies were not included.

The 2 authors assessed the abstracts independently. There were no discrepancies between them and 73 papers were selected for more detailed examination. Of these, 8 (reporting on 7 studies) were selected as relevant to the research question. This required participants to have no diagnosis of dementia at baseline, a CDT score at baseline and some form of longitudinal follow-up.

\section{Results}

Eight papers were identified, reporting on 7 studies. Of these, only 5 studies provided sufficient information to allow evaluation of the $\mathrm{CDT}$ as a predictor. In the one 
that had produced 2 papers, these were based on different populations at different lengths of follow-up, but only 1 provided follow-up data with regard to cognitive decline. All 8 papers are included in table 1.

Three studies had longitudinal data showing that the performance on the CDT was worse in a non-demented population at baseline who went on to develop dementia/cognitive impairment than in those who did not [2123]. Ferrucci et al. [21] followed their population for 4 years and found that when the analyses were restricted to people with an MMSE $>21$ at baseline, pathological clocks were significantly more likely to predict an MMSE $<21$ (5.4 times more likely) or $<18$ (5.5 times more likely) at follow-up. Similarly, Chen et al. [22] observed a difference between baseline CDT scores when comparing those who went on to receive a diagnosis of dementia with those who did not, although it did not achieve statistical significance $(\mathrm{p}=0.11)$. O’Rourke et al. [23] found errors in substitution and clock setting were significantly more likely in the group that went on to have dementia.

Two further studies provided limited information [24, 25]. Brodaty and Moore [24] reported that the CDT identified Alzheimer's disease cases in those with MMSE sores of $\geq 24$. In the Movies study, Ratcliff et al. [25], writing about 425 survivors followed for 10 years, found that constructional praxis (including the CDT) was one of the aspects identified by a factor analysis as impacting on cognitive decline, but they did not relate the CDT to incident dementia or cognitive decline. One further study identified 10 out of 50 subjects as having abnormal clocks. However, only 1 participant accepted later cognitive evaluation [26].

Of the other papers, one, Nishiwaki et al. [27], did not assess dementia as an endpoint, although they found that the CDT score was related to subsequent mortality from cerebrovascular disease, respiratory disease or malignant neoplasm. Another was a second publication using the data from the Movies project, with long-term follow-up but without predictive information [28].

Of the 5 studies with outcome data, only 1 published an odds ratio, 2 provided significance values for comparisons between the cases and controls at follow-up, 1 presented the number of cases identified by each scoring system and 1 considered praxis as a feature emerging from a factor analysis. Meta-analyses using the data identified in the review were therefore not possible as the data were too few and too disparate (table 1).

\section{Discussion}

A systematic review of the literature found 5 useful studies with regard to the application of the CDT as an early test for cognitive decline or dementia prior to more traditional screening tools identifying a problem. The evidence that is available suggests that the CDT may well function in this role, but the data are currently insufficient to allow any firm conclusions. There were many studies identified in the literature showing that the CDT correlated with other tests and with diagnoses, but in total, only 7 investigations could be found that followed a population for a period of time and/or had CDT data at baseline with later outcome. Of these 8 papers (7 studies), only 4 clearly specified the follow-up time and the lack of cognitive decline or dementia at baseline $[21,22,25$, 28], with 1 further study including only MMSE scores $>21$ at baseline [21], a level that may well be indicative of an already present dementing process. The analyses reported in the papers vary too widely to allow a meaningful comparison. The methods used to administer and score the CDT differed, as did the other assessments of cognitive function, the population and the length of follow-up. The identification of cases was not standardised and this may have impacted on the study results and means that drawing conclusions is hard even with the available data. The results were also reported in a variety of ways and there was insufficient statistical information to allow formal comparison, meta-analysis or the production of a forest plot. Despite this, the limited data available do seem to indicate that the CDT may show deficit before the MMSE falls to the usually defined category of 'mild dementia', that is a score $<24$. Certainly, performance on the CDT is likely to be predictive of decline and that in itself may merit its use at least alongside the MMSE, with abnormal performance prompting further assessment even if the MMSE score does not seem to give cause for investigation. Certainly, it is not timeconsuming and can be incorporated into general practice assessments [27]. As the data currently available in the literature are disparate and unable to be combined, it is argued that it is time for a large robust study to answer this question clearly.

\section{Acknowledgements}

The authors would like to thank Professor Christopher Bulpitt for his advice and comment. As first author, I confirm that I have written consent from Professor Bulpitt. 


\section{References}

1 Lobo A, Launer L, Fratiglioni L, et al; Neurologic Diseases in the Elderly Research Group: Prevalence of dementia and major subtypes in Europe: a collaborative study of population based-cohorts. Neurology 2000;54(11): S4-S9.

2 United Nations Population Division DESA: Report on World Population Ageing 19502050. United Nations Population Division DESA, pp xxvii-xxxi.

3 Farlow M: Use of antidementia agents in vascular dementia: beyond Alzheimer's disease. Mayo Clin Proc 2006;81:1350-1358.

4 Spreen O, Strauss E: A Compendium of Neuropsychological Tests. Administration, Norms and Commentary, ed 2. Oxford, Oxford University Press, 1998.

5 Levey A, Lah J, Goldstein F, et al: Mild cognitive impairment: an opportunity to identify patients at high risk for progression to $\mathrm{Alz}$ heimer's disease. Clin Ther 2006;28:9911001.

-6 Folstein W, Folstein S, McHugh R: 'Mini Mental State': a practical method for grading the cognitive state of patients for the clinician. J Psychiatr Res 1975;12:189-198.

$\checkmark 7$ Shulman K, Herrmann N, Brodaty H, et al: IPA survey of brief cognitive screening instruments. Int Psychogeriatr 2006;18:281294.

8 Espino D, Lichtenstein M, Palmer R, et al: Evaluation of the Mini-Mental State Examination's internal consistency in a community-based sample of Mexican-American and European-American elders: results from the San Antonio longitudinal study of aging. J Am Geriatr Soc 2004;52:822-827.

$\checkmark 9$ Kliegel M, Zimprich D, Rott C: Life-long intellectual activities mediate the predictive effect of early education on cognitive impairment in centenarians: a retrospective study. Aging Ment Health 2004;8:430-437.
10 Shulman K: Clock-drawing: is it the ideal cognitive screening test? Int J Geriatr Psychiatry 2000;15:548-561.

11 Herrman N, Kidron D, Shulman K, et al: Clock tests in depression, Alzheimer's dis ease and elderly controls. Int J Psychiatry Med 1998;28:437-447.

12 Gruber N, Varner R, Chen Y, et al: A comparison of the Clock Drawing Test and the Pfeiffer Short Portable Mental Status Questionnaire in a geropsychiatry clinic. Int J Geriatr Psychiatry 1997;12:525-532.

13 Freedman M, Leach L, Kaplan E, et al: Clock Drawing. Oxford, Oxford University Press, 1994.

14 Harciarek M, Jodzio K: Neuropsychological differences between frontotemporal dementia and Alzheimer's disease: a review. Neuropsychol Rev 2005;15:131-145.

15 Baudic S, Dalla Barba G, Thibaudet M, et al: Executive function deficits in early Alzheimer's disease and their relations with episodic memory. Arch Clin Neuropsychol 2006;21:15-21.

16 Rapp M, Reischies F: Attention and executive control predict Alzheimer disease in late life: results from the Berlin Aging study (BASE). Am J Geriatr Psychiatry 2005;13 134-141.

-17 Lamar M, Swenson R, Kaplan E, et al: Characterising alterations in executive functioning across distinct subtypes of cortical and subcortical dementia. Clin Neuropsychol 2004;18:22-31.

18 Albert M, Moss M, Tanzi R, et al: Preclinical prediction of AD using neuropsychological tests. J Int Neuropsychol Soc 2001;7:631639.

19 De Jager C, Hogervorst E, Combrinck M, et al: Sensitivity and specificity of neuropsychological tests for mild cognitive impair ment, vascular cognitive impairment and Alzheimer's disease. Psychol Med 2003;33. 1039-1050.
20 McPherson S, Fairbanks L, Tiken S, et al: Apathy and executive function in Alzheimer's disease. J Int Neuropsychol Soc 2002;8:373381.

21 Ferrucci L, Cecchi F, Guralnik J, et al: Does the clock drawing test predict cognitive decline in older persons independent of the mini-mental state examination? J Am Geriatr Soc 1996;44:1326-1331.

22 Chen P, Ratcliff G, Bele S, et al: Patterns of cognitive decline in presymptomatic Alzheimer disease. Arch Gen Psychiatry 2001; 58:853-858.

23 O’Rourke N, Tuokko H, Hayden S, et al: Early identification of dementia: predictive validity of the clock test. Arch Clin Neuropsychol 1997;12:257-267.

24 Brodaty H, Moore C: The clock drawing test for dementia of the Alzheimer's type: a comparison of three scoring methods in a memory disorders clinic. Int J Geriatr Psychiatry 1997; 12:619-627.

25 Ratcliff G, Dodge H, Birzescu M, et al: Tracking cognitive functioning over time: ten-year longitudinal data from a community-based study. Appl Neuropsychol 2003;10:76-88.

26 Lee A, Beaver H, Jogerst G, et al: Screening elderly patients in an outpatient ophthalmology clinic for dementia, depression, and functional impairment. Ophthalmology 2003;110:651-657

27 Nishiwaki Y, Breeze E, Smeeth L, et al: Validity of the clock-drawing test as a screening tool in the elderly. Am J Epidemiol 2004;160: 797-807.

28 Ganguli M, Seaberg E, Ratcliff G, et al: Cognitive stability over 2 years in a rural elderly population the Movies project. Neuroepidemiology 1996;15:42-50. 